\title{
Measurement of the Radial Nerve Danger Zone in Filipino Adults: A Cadaveric Study
}

\author{
Rubio DA', MD, Pacheco A', MD, Abrilla A $^{2}, M D$ \\ 'Philippine General Hospital, University of the Philippines Manila, Manila, Philippines \\ ${ }^{2}$ College of Medicine, University of the Philippines Manila, Manila, Philippines

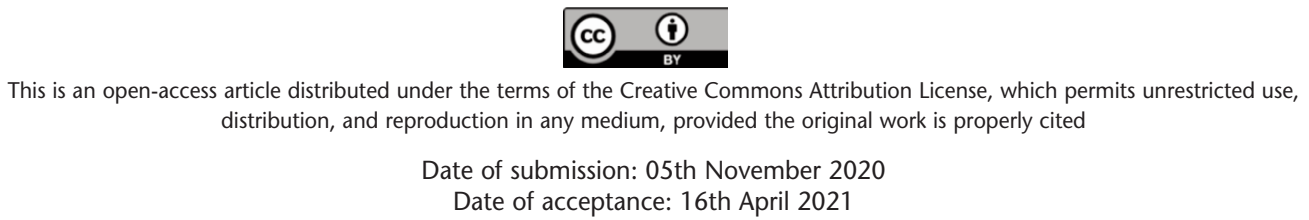

\section{ABSTRACT}

Introduction: The radial nerve danger zone (RNDZ) is an important anatomic consideration to anticipate or prevent injury in trauma assessment or surgical fixation. No published estimate currently exists for Filipinos. In this study, we sought to provide a local estimate and explore potential predictors of this anatomic region in Filipino adult cadavers.

Materials and methods: Posterior dissection to expose and measure the radial nerve, from the lateral epicondyle to the lateral intermuscular septum, was performed in 60 upper limbs from 30 formalin-preserved cadavers in the laboratory of the Department of Anatomy, College of Medicine, University of the Philippines Manila. Univariate and multivariate linear regression modelling was performed with RNDZ as the dependent variable and age, sex, height and humeral length as potential independent variables individually and in combinations.

Results: The mean radial nerve length from the lateral epicondyle to the lateral intermuscular septum was estimated at $10.6 \mathrm{~cm}$ (95\% confidence interval: $10.3 \mathrm{~cm}, 10.9 \mathrm{~cm})$. Height and humeral length were statistically significant univariate predictors in female cadavers, while only height was significant in male cadavers. In addition, all multivariate regression models were statistically significant and accounted for more than $57 \%$ of the variability in female RNDZ estimates. In comparison, only models that included height and age were statistically significant predictors of RNDZ and accounted for at most $22 \%$ of the variability of the estimate in males.

Conclusion: The estimated length of the radial nerve danger zone generated in this study should be strongly considered over other published estimates in surgical fixation procedures performed in adult Filipinos.

\section{Keywords:}

cadaver, danger zone, Filipino, humerus, radial nerve

\section{INTRODUCTION}

The radial nerve provides substantial motor and sensory function to the upper extremity. Arising from the posterior cord of the brachial plexus, this nerve crosses medial to lateral obliquely, along with accompanying vessels, over the posterior surface of the humeral spiral groove. It then penetrates the lateral intramuscular septum near the junction of the middle and distal thirds of the humerus ${ }^{1}$. Disruption of this structure often leads to clinically relevant motor consequences, such as the inability to extend the elbow, wrist and fingers and paraesthesia along its sensory distribution. Such palsy often complicates conditions or interventions involving the humerus, which is often attributed to the intimate association between the course of the nerve and the long bone in question ${ }^{2}$.

Approximately 5\% to $30 \%$ of such injuries are iatrogenic, secondary to humeral surgical fixation instruments (such as surgical blades, Kirschner wires, plates and screws, and external fixators) and procedures (such as fracture manipulation, limb traction and even improper positioning on the operating table $)^{3-6}$. Since this aetiology or mechanism is preventable, at least theoretically, orthopaedic surgeons having a comprehensive understanding of the anatomical relations of the radial nerve is a must. Furthermore, in order to describe further the anatomical relations of the radial nerve along its tract in the distal humerus, its direct visualisation is necessary; this, in turn, will help design measures to avoid injuring the nerve during surgical management.

A component of this practical knowledge is the so-called "danger zone" of the radial nerve, a region in the distal humerus where the nerve runs posteriorly from lateral epicondyle to the lateral intermuscular septum and where surgical fixation must be avoided, lest the risk for radial nerve palsy is substantially heightened ${ }^{3,7}$. Various estimates for this region exist in the literature, with some studies

Corresponding Author: Donnel Alexis Ting Rubio, Department of Orthopaedics, College of Medicine and Philippine General Hospital, University of the Philippines Manila, Taft Avenue, 1000 Manila, Philippines

Email: dtrubio1@up.edu.ph 
showing large variability in the course of the nerve within the $6 \mathrm{~cm}$ to $16 \mathrm{~cm}$ range $e^{8,9}$. Nevertheless, the applicability of these estimates in the Filipino anatomy remains yet to be established.

This study thus aimed to generate an estimate of the radial nerve danger zone (RNDZ) in adult Filipino cadavers.

\section{MATERIALS AND METHODS}

This observational cross-sectional study was reviewed by the University of the Philippines Manila Research Ethics Board (under protocol code 2020-583-EX) in line with the 2017 Philippine National Ethical Guidelines for Health and Health-Related Research ${ }^{10}$. The procedures performed herein followed the technical and ethical standards of the institutional affiliations of all investigators. All formalinpreserved cadavers from the teaching laboratory of the Department of Anatomy, College of Medicine, the University of the Philippines Manila at the time of study implementation were considered. The age at death and anatomic sex of each cadaver were also obtained from anonymised institutional records. Upper limbs with gross apparent upper extremity deformities, if any, were excluded.

After measuring and recording the height of each cadaver and the lengths of their humeri with a tape measure, a posterior dissection of the distal humeral area was performed to expose the lateral epicondyle. The radial nerve was then located with its course followed up to the lateral intermuscular septum. In the process, the said nerve was not manipulated to maintain its preserved anatomic relations. The RNDZ - the length of the exposed radial nerve in the posterior arm from the lateral epicondyle to its insertion to the lateral intermuscular septum - was measured and recorded in each upper limb through a Vernier calliper (Fig. $1)$.

Mean, standard deviation (SD) and 95\% confidence interval (CI) were utilised to generate summary estimates of cadaver height, humeral length and the danger zone, with stratification by recorded anatomic sex. To assess the statistically significant difference at $\mathrm{p}<0.0500$, unequal variances (Welch) t-test was performed to compare the summary measures in terms of upper limb laterality and recorded anatomic sex. The absence of statistically significant difference (set at $\mathrm{p}>0.0500$ ) between left and right humeral length and danger zone was used to further analyse the measurements without regard to laterality or sex. To determine whether any or a combination of the other measured variables predict the danger zone, linear regression analyses were also performed. Stata/IC version $14.2^{11}$ was utilised for these analytical purposes.

\section{RESULTS}

A total of 30 cadavers (12 females and 18 males), each with two intact upper limbs, were included in the study (Table I). The mean (SD) age at death of the cadavers were 52.4 (16.8) years, ranging between 24 and 83 years, and the mean (SD) height was $157.4(9.4) \mathrm{cm}$. The mean (SD) length of both the left and right humeri was estimated at $30.2(2.4) \mathrm{cm}$ (difference not statistically significant, $p=0.1136$ ). In comparison, the mean (SD) left, and right RNDZ (the length of the exposed nerve from the lateral epicondyle to the lateral intermuscular septum insertion) were measured at 10.6 (1.1) $\mathrm{cm}$ and $10.6(1.2) \mathrm{cm}$ (difference not statistically significant, $\mathrm{p}=0.9399)$, respectively.

While the cadavers compared by sex at birth revealed statistically similar mean age $(p=0.2938)$, the male cadavers were taller (mean [95\% CI] difference in height: $12.1 \mathrm{~cm}$ $[6.4 \mathrm{~cm}, 17.9 \mathrm{~cm}], \mathrm{p}=0.0002)$ and had longer left $(2.1 \mathrm{~cm}[0.3$ $\mathrm{cm}, 3.9 \mathrm{~cm}], \mathrm{p}=0.0214)$ and right $(2.2 \mathrm{~cm}[0.5 \mathrm{~cm}, 3.9 \mathrm{~cm}], \mathrm{p}$ $=0.0150)$ humeri than female cadavers. Nevertheless, the left $(\mathrm{p}=0.3477)$ and right $(\mathrm{p}=0.3302)$ RNDZ did not statistically differ by this stratification, as were the left and right humeral lengths ( $p>0.0500$ in all comparisons). As the danger zone did not statistically differ by sex at birth and laterality, the pooled mean $(95 \% \mathrm{CI})$ estimate for this parameter, using the entire sample and disregarding laterality (60 upper limbs in total), is $10.6 \mathrm{~cm}(10.3 \mathrm{~cm}, 10.9 \mathrm{~cm})$, or $34.8 \%(33.4 \%, 36.2 \%)$ of the humeral length (Fig. 2).

With the data collected for age at death, sex at birth, height and humeral length in each cadaver as potential predictors, univariate linear regression analyses with the RNDZ as the dependent variable were performed. Among females $(n=12$, 24 upper limbs), height and humeral length positively correlated with the RNDZ and were revealed to account for $57.74 \%$ and $17.83 \%$, respectively, of the variation in this measure $(p<0.0500$ in both cases, Table II). On the other hand, height was the only statistically significant predictor of this variable in males ( $\mathrm{n}=18,36$ upper limbs), accounting for only $13.57 \%$ of the observed variation. When the cadavers were analysed regardless of sex, height $\left(\mathrm{R}^{2}=\right.$ $22.68 \%)$ and humeral length $\left(\mathrm{R}^{2}=9.54 \%\right)$ emerged as statistically significant predictors of the dependent variable.

Multivariate linear regression analyses with the RNDZ as the dependent variable showed that combining height and at least one other variable incrementally increased the predictive power of the model compared to height alone in the whole sample (Table III). While considering all other variables (height, humeral length, age and sex) as predictors accounts for the highest proportion of variance in the danger zone $\left(\mathrm{R}^{2}=29.55 \%\right)$, a minimal decline in this metric was observed when the humeral length was not considered $\left(\mathrm{R}^{2}=\right.$ $29.47 \%$ ). Sex-disaggregated analyses revealed that all model sets predicted the RNDZ in females with statistical 
Table I: Measured characteristics of the cadavers included in the study

\begin{tabular}{|c|c|c|c|c|}
\hline Variable & $\begin{array}{c}\text { Total } \\
(n=30)\end{array}$ & $\begin{array}{l}\text { Females } \\
(n=12)\end{array}$ & $\begin{array}{l}\text { Males } \\
(n=18)\end{array}$ & p-value \\
\hline Age in years, mean (SD) & $52.4(16.8)$ & $56.6(19.0)$ & $49.6(15.0)$ & 0.2937 \\
\hline Height in $\mathrm{cm}$, mean (SD) & $157.4(9.4)$ & $150.1(7.8)$ & $162.2(7.0)$ & $0.0002 *$ \\
\hline \multicolumn{5}{|c|}{ Humeral length in $\mathrm{cm}$, mean (SD) } \\
\hline Left (30 limbs) & $30.2(2.4)$ & $29.0(2.4)$ & $31.1(2.0)$ & $0.0214 *$ \\
\hline Right (30 limbs) & $30.2(2.4)$ & $28.9(2.3)$ & $31.0(2.0)$ & $0.0150 *$ \\
\hline Pooled (60 limbs) & $30.2(2.4)$ & $28.9(2.3)$ & $31.1(2.0)$ & $0.0006^{*}$ \\
\hline \multicolumn{5}{|c|}{ Danger zone in $\mathrm{cm}$, mean (SD) } \\
\hline Left (30 limbs) & $10.6(1.1)$ & $10.4(0.9)$ & $10.8(1.3)$ & 0.3477 \\
\hline Right (30 limbs) & $10.6(1.2)$ & $10.4(0.9)$ & $10.8(1.3)$ & 0.3302 \\
\hline Pooled (60 limbs) & $10.6(1.1)$ & $10.4(0.9)$ & $10.8(1.3)$ & 0.1669 \\
\hline \multicolumn{5}{|c|}{$\begin{array}{l}\text { Danger zone as percentage (\%) } \\
\text { of humeral length, mean (SD) }\end{array}$} \\
\hline Left (30 limbs) & 35.3 (3.9) & 36.1 (3.4) & $34.7(4.2)$ & 0.3474 \\
\hline Right (30 limbs) & $35.3(3.9)$ & $36.1(3.1)$ & $34.9(4.2)$ & 0.3750 \\
\hline Pooled (60 limbs) & $35.3(3.9)$ & $36.1(3.2)$ & $34.8(4.2)$ & 0.1865 \\
\hline
\end{tabular}

*Significant at $\mathrm{p}<0.05$

Abbreviation - $\mathrm{cm}$ : centimetre, $\mathrm{n}$ : number of cadavers, SD: standard deviation

Table II: Univariate linear regression analysis results for radial nerve danger zone (RNDZ) in female, male and the whole sample of cadavers

\begin{tabular}{|c|c|c|c|c|c|}
\hline Potential Predictor & Coefficient (SE) & p-value & $\mathbf{R}$ & $\mathbf{R}^{2}$ & Intercept (SE) \\
\hline $\begin{array}{l}\text { Female Subset of Sample } \\
\text { Age } \\
\quad \text { Equation: RNDZ }=10.7279-0.0059(\mathrm{~A})\end{array}$ & $-0.0059(0.0010)$ & 0.5621 & 0.1245 & 0.0155 & $10.7279(0.5926)$ \\
\hline $\begin{array}{l}\text { Height } \\
\qquad \text { Equation: RNDZ }=0.0875(\mathrm{H})-2.7321\end{array}$ & $0.0875(0.0160)$ & $0.0000 *$ & 0.7599 & 0.5774 & $-2.7321(2.3976)$ \\
\hline $\begin{array}{l}\text { Humeral length } \\
\quad \text { Equation: RNDZ }=0.1584(L)+5.8148\end{array}$ & $0.1584(0.0725)$ & $0.0398 *$ & 0.4223 & 0.1783 & $5.8148(2.1029)$ \\
\hline $\begin{array}{l}\text { Male Subset of Sample } \\
\text { Age } \\
\quad \text { Equation: RNDZ }=11.4976-0.0144(\mathrm{~A})\end{array}$ & $-0.0144(0.0145)$ & 0.3285 & 0.1676 & 0.0281 & $11.4976(0.7507)$ \\
\hline $\begin{array}{l}\text { Height in } \mathrm{cm} \\
\quad \text { Equation: } \mathrm{RNDZ}=0.0677(\mathrm{H})-0.1988\end{array}$ & $0.0677(0.0293)$ & 0.0271 * & 0.3684 & 0.1357 & $-0.1988(4.7576)$ \\
\hline $\begin{array}{l}\text { Humeral length in } \mathrm{cm} \\
\quad \text { Equation: } \mathrm{RNDZ}=0.1225(\mathrm{~L})+5.8148\end{array}$ & $0.1225(0.1062)$ & 0.2568 & 0.1942 & 0.0377 & $5.8148(2.1029)$ \\
\hline $\begin{array}{l}\text { Full Aggregate of Sample } \\
\text { Age } \\
\text { Equation: RNDZ }=11.2574-0.0120 \text { (A) }\end{array}$ & $-0.0120(0.0088)$ & 0.1793 & 0.1676 & 0.1758 & $11.2574(0.4851)$ \\
\hline $\begin{array}{l}\text { Female sex } \\
\qquad \text { Equation: RNDZ }=10.7833-0.3875(F)\end{array}$ & $-0.3875(0.2975)$ & 0.1979 & 0.1685 & 0.0284 & $10.7833(0.1882)$ \\
\hline $\begin{array}{l}\text { Male sex } \\
\quad \text { Equation: } \mathrm{RNDZ}=0.3875(\mathrm{M})+10.3958\end{array}$ & $0.3875(0.2975)$ & 0.1979 & 0.1685 & 0.0284 & $10.3958(0.2305)$ \\
\hline $\begin{array}{l}\text { Height in } \mathrm{cm} \\
\qquad \text { Equation: } \mathrm{RNDZ}=0.0581(\mathrm{H})+1.4851\end{array}$ & $0.0581(0.0141)$ & 0.0001 * & 0.4762 & 0.2268 & $1.4851(2.2203)$ \\
\hline $\begin{array}{l}\text { Humeral length in } \mathrm{cm} \\
\quad \text { Equation: } \mathrm{RNDZ}=0.1476(\mathrm{~L})+6.1698\end{array}$ & $0.1476(0.0597)$ & $0.0164 *$ & 0.3089 & 0.0954 & $6.1698(1.8084)$ \\
\hline
\end{tabular}

*Significant at $\mathrm{p}<0.05$

Abbreviation - A: age in years, F: female (input is "1" if the particular cadaver is female, "0" if male), H: height in centimetres (cm), L: humeral length in $\mathrm{cm}, \mathrm{M}$ : male (input is " 1 " if the particular cadaver is male, " 0 " if female), RNDZ: radial nerve danger zone in cm, SE: standard error 
Table III: Multivariate regression model building results with danger zone as the dependent variable

\begin{tabular}{|c|c|c|c|}
\hline Predictor Model Set & Equation & p-value & $\mathbf{R}^{2}$ \\
\hline \multicolumn{4}{|l|}{ Female Subset of Sample } \\
\hline Height, age & RNDZ $=0.0869(\mathrm{H})-0.0022(\mathrm{~A})-2.5251$ & $0.0001 *$ & 0.5795 \\
\hline Height, humeral length & RNDZ $=0.0847(\mathrm{H})-0.0179(\mathrm{~L})-2.8296$ & $0.0001 *$ & 0.5790 \\
\hline Height, humeral length, age & $R N D Z=0.0554(H)+0.0089(L)-0.0101(A)+2.1738$ & $0.0004 *$ & 0.5858 \\
\hline \multicolumn{4}{|l|}{ Male Subset of Sample } \\
\hline Height, age & RNDZ $=0.0821(\mathrm{H})-0.0248(\mathrm{~A})-1.3032$ & $0.0192 *$ & 0.2129 \\
\hline Height, humeral length & RNDZ $=0.0737(\mathrm{H})-0.0335(\mathrm{~L})-0.1334$ & 0.0872 & 0.1374 \\
\hline Height, humeral length, age & RNDZ $=0.0950(\mathrm{H})-0.0682(\mathrm{~L})-0.0260(\mathrm{~A})-1.2204$ & $0.0446^{*}$ & 0.2200 \\
\hline \multicolumn{4}{|l|}{ Full Aggregate of Sample } \\
\hline Height, age & RNDZ $=0.0569(\mathrm{H})-0.0099(\mathrm{~A})+2.1872$ & $0.0003 *$ & 0.2478 \\
\hline Height, sex & RNDZ $=0.0765(\mathrm{H})-0.5392(\mathrm{~S})-0.5468$ & $0.0002 *$ & 0.2591 \\
\hline Height, humeral length & $R N D Z=0.0600(H)-0.0113(L)+1.5198$ & $0.0006 *$ & 0.2271 \\
\hline Height, age, sex & RNDZ $=0.0793(\mathrm{H})-0.0132(\mathrm{~A})-0.6659(\mathrm{~S})-0.0872$ & $0.0002 *$ & 0.2947 \\
\hline Height, humeral length, age & $R N D Z=0.0554(H)+0.0089(L)-0.0101(A)+2.1738$ & $0.0011 *$ & 0.2480 \\
\hline Height, humeral length, sex & $\mathrm{RNDZ}=0.0780(\mathrm{H})-0.0089(\mathrm{~L})-0.5384(\mathrm{~S})-0.5163$ & $0.0007 *$ & 0.2593 \\
\hline Height, humeral length, age, sex & $R N D Z=0.0762(H)+0.0189(L)-0.0137(A)-0.6719(S)-0.1366$ & $0.0006 *$ & 0.2955 \\
\hline
\end{tabular}

*Significant at $\mathrm{p}<0.05$.

Abbreviation - A: age in years, $\mathrm{H}$ : height in centimetres $(\mathrm{cm}), \mathrm{L}$ : humeral length in $\mathrm{cm}, \mathrm{RNDZ}$ : radial nerve danger zone in $\mathrm{cm}, \mathrm{S}$ : sex $(0$ $=$ female, 1 = male), SE: standard error

Table IV: Estimates of the radial nerve danger zone, measured from the lateral epicondyle to the lateral intermuscular septum, as reported in the literature

\begin{tabular}{|c|c|c|c|c|}
\hline Study & Country & $\mathbf{n}$ & $\begin{array}{l}\text { Measured RNDZ } \\
\text { Mean } \pm \text { SD }(\mathrm{cm})\end{array}$ & Statistical Rank* \\
\hline Gerwin et al (1996) ${ }^{14}$ & USA & 10 & $14.2 \pm 0.6$ & 1 \\
\hline Guse and Ostrum (1995) ${ }^{15}$ & USA & 24 & $12.6 \pm 1.1$ & 2 \\
\hline Bono et al $(2000)^{16}$ & USA & 50 & $12.3 \pm 2.3$ & 2 \\
\hline Artico et al (2009) $)^{12}$ & Italy & 30 & $12.1 \pm 1.3$ & 2 \\
\hline Simone et al (2009) ${ }^{17}$ & USA & 10 & $12.2 \pm 1.0$ & 3 \\
\hline Carlan et al (2007) & USA & 27 & $10.9 \pm 1.5$ & 4 \\
\hline This study & Philippines & 60 & $10.6 \pm 1.1$ & 4 \\
\hline Chou et al (2008) ${ }^{7}$ & Taiwan & 120 & $10.4 \pm 2.5$ & 4 \\
\hline Fleming et al (2004) ${ }^{9}$ & Ireland & 20 & $10.2 \pm 0.8$ & 4 \\
\hline
\end{tabular}

*Determined by running the estimates in one-way analysis of variance followed by Tukey-Kramer post-hoc test; lower rank indicates statistically longer estimate and studies with the same rank indicate lack of statistically significant difference between their estimates, both at $\mathrm{p}<0.05$.

Abbreviations - cm: centimetre, n: number of upper extremities considered, RNDZ: radial nerve danger zone, SD: standard deviation, USA: United States of America

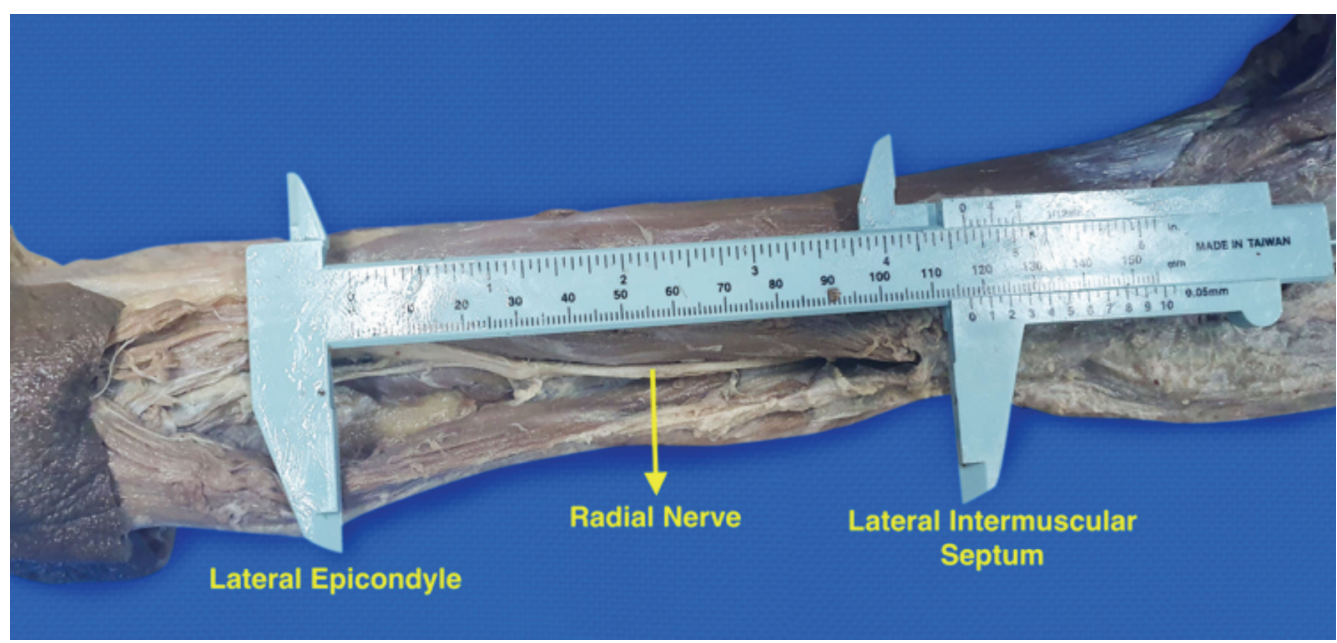

Fig. 1: Measurement orientation of radial nerve danger zone from the tip of the lateral epicondyle to the lateral intermuscular septum. 


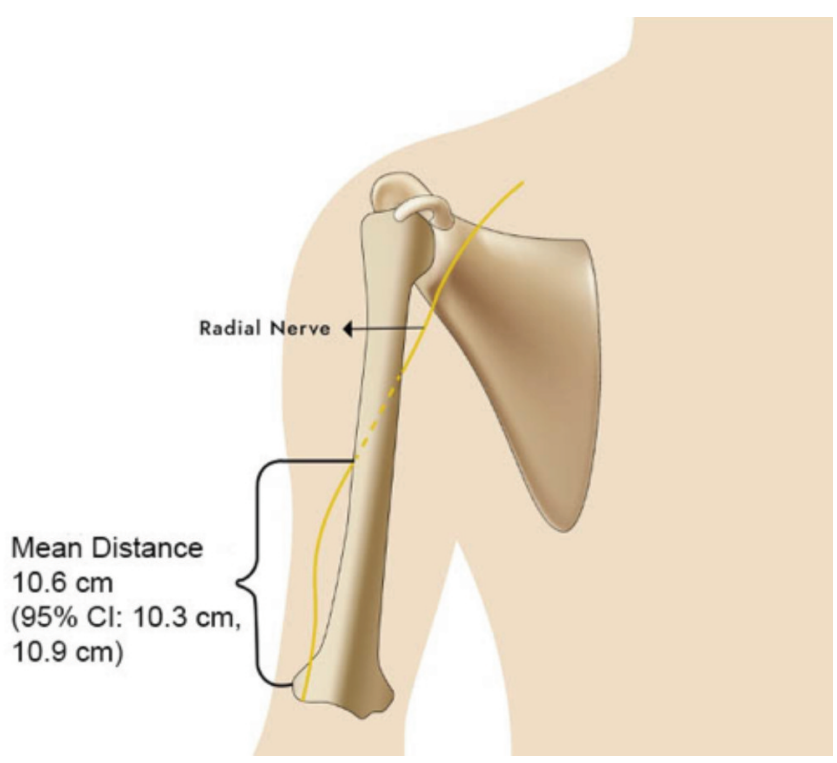

Fig. 2: Graphic representation of the estimated mean radial nerve danger zone (RNDZ), the distance from the lateral epicondyle to the lateral intermuscular septum at the spiral groove, from the studied cadavers. (Cl: confidence interval).

significance and $\mathrm{R}^{2}>57 \%$. On the other hand, only multivariate models that included height and age were statistically significant predictors of RNDZ in males, albeit accounting for its variability to a lesser extent than those for females $\left(\mathrm{R}^{2}<22.00 \%\right)$.

\section{DISCUSSION}

In this study of Filipino formalin-preserved cadavers, we estimated the mean RNDZ, measured from the lateral epicondyle to the exit point of the nerve in the lateral intermuscular septum, to be $10.6 \mathrm{~cm}(95 \% \mathrm{CI}: 10.3 \mathrm{~cm}$, $10.9 \mathrm{~cm})$. This estimate is comparable with the estimate from investigations in Taiwan ${ }^{7}$ and Ireland ${ }^{9}$ while being statistically smaller than those from Italy ${ }^{12}$ (Table IV). However, compared to data from the United States, our estimate is similar to that of only one ${ }^{13}$ and is statistically smaller than those from the remaining four studies ${ }^{14-17}$. This raises the possibility of the RNDZ being truly smaller in Filipino adult patients compared to other nationalities (especially in most non-Asian ones), and this has contextual implications for the conduct of relevant surgical interventions in this population. While we also noted that female cadavers in our study had statistically shorter height and humeral length than their male counterparts, this may likely be ungeneralisable and influenced by the minuteness of the sample size relative to the Filipino population. The RNDZ between the sexes, however, were observed to be similar.

Furthermore, we have demonstrated that this anatomic parameter can be predicted to a certain extent using routinely collected patient information and easily obtainable intraoperative measurements. However, (1) it remains to be seen whether this would have relevant use in the future and (2) a larger sample and/or variable list may be needed to generate valid and reliable predictive models to this end. Regardless of the uncertainty on the value of these predictive models, an interesting secondary finding was the propensity of the variability in male RNDZ estimates to be less accounted for by the designated independent variables, individually and in combinations, than that in females.

With the increasing appeal of surgical management for humeral shaft fractures, either to allow early mobilisation or for temporary fixation, a proper understanding of the anatomic location of the radial nerve is crucial to avoid iatrogenic injury ${ }^{4}$. External fixation involving the humerus should be made cautiously, especially regarding inserting percutaneous pins over the distal aspect. Several studies, mostly case reports and series, highlight the occurrence of radial nerve palsy after percutaneous application of external fixator $^{18-23}$. For open reduction and internal fixation cases using plate and screws (either the standard open or the minimally invasive plate osteosynthesis [MIPO] technique), nerve injury may occur when the plate is placed over or under the nerve and due to the surgical approach used (lateral or posterior). Insertion of intramedullary nails for humeral shaft fractures may also put the radial nerve at risk as placing the interlocking screw over the distal portion from lateral to medial may inadvertently damage this tissue ${ }^{8}$. In a recent survey of 151 patients with humeral shaft fracture who underwent internal fixation through plate osteosynthesis or intramedullar nailing, $9(6 \%)$ were noted to have sustained secondary radial nerve palsy; 4 from open plate osteosynthesis, 3 from MIPO, 1 from intramedullary nailing and 1 from percutaneous external fixator application ${ }^{24}$. Removal of implants, especially with scarred tissue, will incur less risk if we can predict pre-operatively the radial 
nerve and its orientation, position and location in the distal humerus 9 . All in all, a well-informed and careful estimation of the positioning of the radial nerve, especially with regards to its anatomic relations, is paramount in ensuring a surgery with minimised adverse outcomes.

We recommend the conduct of further local cadaveric studies of similar objectives to determine whether the results of this study are replicable. Furthermore, intraoperative investigations involving consenting live patients undergoing surgery for related diseases (in the anatomic area of concern) should also be considered; such a strategy may remove the potential extraneous influence of biological death and cadaver preservation in RNDZ ascertainment. Finally, other relevant anatomical-surgical parameters other than the danger zone may also be investigated, and endeavours that would permit better RNDZ prediction (preferably using conveniently obtained parameters) are strongly encouraged.

\section{CONCLUSION}

This cadaveric study provides, for the first time, an estimate of the RNDZ in Filipino adults. Understanding the possible location of the radial nerve over the distal humerus, with blunt dissection and proper visualisation of the nerve, will aid the orthopaedic surgeon in avoiding iatrogenic radial nerve palsy during patient management.

\section{ACKNOWLEDGEMENTS}

The authors are grateful for the invaluable assistance of the technical staff, particularly Jupiter Kelly Barroa, of the Department of Anatomy, College of Medicine, University of the Philippines Manila. We also thank Dianne Valeria Rubio for providing the graphic representation of the measured distance from the lateral epicondyle to the lateral intermuscular septum (Fig. 1).

\section{CONFLICT OF INTEREST}

The authors declare no conflict of interest.

\section{REFERENCES}

1. Moore KL, Dalley AF, Agur AMR. Clinically Oriented Anatomy. 7th ed. Pennsylvania: Wolters Kluwer Health/Lippincott Williams and Wilkins; 2014. 1134 p.

2. Ljungquist KL, Martineau P, Allan C. Radial nerve injuries. J Hand Surg Am. 2015; 40(1): 166-72. doi: 10.1016/j.jhsa.2014.05.010

3. Rocchi M, Tarallo L, Mugnai R, Adani R. Humerus shaft fracture complicated by radial nerve palsy: is surgical exploration necessary? Musculoskelet Surg. 2016; 100(Suppl 1): 53-60. doi: 10.1007/s12306-016-0414-3

4. Jain RK, Champawat VS, Mandlecha P. Danger zone of radial nerve in Indian population - a cadaveric study. J Clin Orthop Trauma. 2019; 10(3): 531-4. doi: 10.1016/j.jcot.2018.02.006

5. Bumbasirevic M, Palibrk T, Lesic A, Atkinson H. Radial nerve palsy. EFORT Open Rev. 2017; 1(8): 286-94. doi: 10.1302/20585241.1 .000028

6. Paterson AJ, Wiid AY, Navsa N, Bosman MC. The safe zone for placement of external fixation on the distal humerus: a cadaveric study. Orthop Proc. 2018; 96-B: SUPP_19. doi: 10.1302/1358-992X.96BSUPP_19.SAOA2014-052

7. Chou PH, Shyu JF, Ma HL, Wang ST, Chen TH. Courses of the radial nerve differ between Chinese and Caucasians: clinical applications. Clin Orthop Relat Res. 2008; 466(1): 135-8. doi: 10.1007/s11999-007-0019-0

8. Reichert P, Wnukiewicz W, Witkowski J, Bochenska A, Mizia S, Gosk J, et al. Causes of secondary radial nerve palsy and results of treatment. Med Sci Monit. 2016; 22: 554-62. doi: 10.12659/MSM.897170

9. Fleming P, Lenehan B, Sankar R, Folan-Curran J, Curtin W. One-third, two-thirds: relationship of the radial nerve to the lateral intermuscular septum in the arm. Clin Anat. 2004; 17(1): 26-9. doi: 10.1002/ca.10181

10. Philippine Health Research Ethics Board. National Ethical Guidelines for Health and Health-Related Research 2017.2018. https://drive.google.com/file/d/1acacYXFpeaUlHyLJU1PjQAJS9KrForhG/view (accessed on 15 October 2020)

11. Stata/IC version 14.2. College Station, Texas, United States of America: StataCorp LLC; 2016. https://www.stata.com/stata14/ (accessed on 1 August 2020) 
12. Artico M, Telera S, Tiengo C, Stecco C, Macchi V, Porzionato A, et al. Surgical anatomy of the radial nerve at the elbow. Surg Radiol Anat. 2009; 31(2): 101-6. doi: 10.1007/s00276-008-0412-8

13. Carlan D, Pratt J, Patterson JM, Weiland AJ, Boyer MI, Gelberman RH. The radial nerve in the brachum: an anatomic study in human cadavers. J Hand Surg Am. 2007; 32(8): 1177-82. doi: 10.1016/j.jhsa.2006.07.001

14. Gerwin M, Hotchkiss RN, Weiland AJ. Alternative operative exposures of the posterior aspect of the humeral diaphysis with reference to the radial nerve. J Bone Joint Surg. 1996; 78(11): 1690-5. doi: 10.2106/00004623-199611000-00008

15. Guse TR, Ostrum RF. The surgical anatomy of the radial nerve around the humerus. Clin Orthop Relat Res. 1995; (320): 14953.

16. Bono CM, Grossman MG, Hochwald N, Tornetta P 3rd. Radial and axillary nerves. Anatomic considerations for humeral fixation. Clin Orthop Relat Res. 2000; (373): 259-64.

17. Simone JP, Streubel PN, Sánchez-Sotelo J, Steinmann SP, Adams JE. Fingerbreadths rule in determining the safe zone of the radial nerve and posterior interosseous nerve for a lateral elbow approach: an anatomic study. J Am Acad Orthop Surg Glob Res Rev. 2019; 3(2): e005. doi: 10.5435/JAAOSGlobal-D-19-00005

18. Trigo L, Sarasquete J, Noguera L, Proubasta I, Lamas C. Radial nerve injury following elbow external fixator: report of three cases and literature review. Arch Orthop Trauma Surg. 2017; 137(7): 953-7. doi: 10.1007/s00402-017-2711-1

19. Tomaino MM, Sotereanos DG, Westkaemper J, Plakseychuk A. Posterior interosseous nerve palsy following placement of the compass elbow hinge for acute instability: a case report. J Hand Surg Am. 1999; 24(3): 554-60. doi: 10.1053/jhsu.1999.0554

20. Fox RJ, Varitimidis SE, Plakseychuk A, Vardakas DG, Tomaino MM, Sotereanos DG. The Compass Elbow Hinge: indications and initial results. J Hand Surg Br. 2000; 25(6): 568-72. doi: 10.1054/jhsb.2000.0425

21. Baumann G, Nagy L, Jost B. Radial nerve disruption following application of a hinged elbow external fixator: a report of three cases. J Bone Joint Surg Am. 2011; 93(10): e51. doi: 10.2106/JBJS.J.00436

22. Ring D, Bruinsma WE, Jupiter JB. Complications of hinged external fixation compared with cross-pinning of the elbow for acute and subacute instability. Clin Orthop Relat Res. 2014; 472(7): 2044-8. doi: 10.1007/s11999-014-3510-4

23. Poglia P, Wehrli L, Steinmetz S, Zermatten P. Radial nerve palsy after the use of an adjuvant hinged external fixator in a complex fracture-dislocation of the elbow: a case report and review of the literature. J Med Case Rep. 2016; 10(1): 121. doi: 10.1186/s13256-016-0904-9

24. Schwab TR, Stillhard PF, Schibli S, Furrer M, Sommer C. Radial nerve palsy in humeral shaft fractures with internal fixation: analysis of management and outcome. Eur J Trauma Emerg Surg. 2018; 44(2): 235-43. doi: 10.1007/s00068-017-0775-9 